\title{
Oscillatory Stability and Eigenvalue Sensitivity Analysis of A DFIG Wind Turbine System
}

Yang, Lihui; Xu, Zhao; Østergaard, Jacob; Dong, Zhao Yang; Wong, Kit Po; Ma, Xikui

Published in:

IEEE Transactions on Energy Conversion

Link to article, DOI:

10.1109/TEC.2010.2091130

Publication date:

2011

Document Version

Publisher's PDF, also known as Version of record

Link back to DTU Orbit

Citation (APA):

Yang, L., Xu, Z., Østergaard, J., Dong, Z. Y., Wong, K. P., \& Ma, X. (2011). Oscillatory Stability and Eigenvalue Sensitivity Analysis of A DFIG Wind Turbine System. IEEE Transactions on Energy Conversion, 26(1), 328-339. https://doi.org/10.1109/TEC.2010.2091130

\section{General rights}

Copyright and moral rights for the publications made accessible in the public portal are retained by the authors and/or other copyright owners and it is a condition of accessing publications that users recognise and abide by the legal requirements associated with these rights.

- Users may download and print one copy of any publication from the public portal for the purpose of private study or research.

- You may not further distribute the material or use it for any profit-making activity or commercial gain

- You may freely distribute the URL identifying the publication in the public portal 


\title{
Oscillatory Stability and Eigenvalue Sensitivity Analysis of A DFIG Wind Turbine System
}

\author{
Lihui Yang, Zhao Xu, Member, IEEE, Jacob Østergaard, Senior Member, IEEE, \\ Zhao Yang Dong, Senior Member, IEEE, Kit Po Wong, Fellow, IEEE, and Xikui Ma
}

\begin{abstract}
This paper focuses on modeling and oscillatory stability analysis of a wind turbine with doubly fed induction generator (DFIG). A detailed mathematical model of DFIG wind turbine with vector-control loops is developed, based on which the loci of the system Jacobian's eigenvalues have been analyzed, showing that, without appropriate controller tuning a Hopf bifurcation can occur in such a system due to various factors, such as wind speed. Subsequently, eigenvalue sensitivity with respect to machine and control parameters is performed to assess their impacts on system stability. Moreover, the Hopf bifurcation boundaries of the key parameters are also given. They can be used to guide the tuning of those DFIG parameters to ensure stable operation in practice. The computer simulations are conducted to validate the developed model and to verify the theoretical analysis.
\end{abstract}

Index Terms-Doubly fed induction generator (DFIG), eigenvalue sensitivity, Hopf bifurcation, stability.

\section{INTRODUCTION}

D OUBLY fed induction generator (DFIG) is a popular wind turbine system due to its high energy efficiency, reduced mechanical stress on the wind turbine, and relatively low power rating of the connected power electronics converter. The DFIG is also complex involving aerodynamical, electrical, and mechanical systems. With increasing penetration level of DFIG-type wind turbines into the grid, the stability issue of DFIG is of great importance to be properly investigated.

A DFIG system, including induction generator, two-mass drive train, power converters, and feedback controllers, is a

Manuscript received November 30, 2009; revised June 21, 2010 and August 31, 2010; accepted October 29, 2010. Date of publication January 6, 2011; date of current version February 18, 2011. Paper no. TEC-00508-2009.

L. Yang and X. Ma are with School of Electrical Engineering, Xi'an Jiaotong University, Xi'an 710049, China (e-mail: lihui.yang@mail.xjtu.edu.cn; maxikui@mail.xjtu.edu.cn).

Z. Xu was with the Center for Electric Technology, Department of Electrical Engineering, Technical University of Denmark, DK-2800 Lyngby, Denmark. He is now with the Department of Electrical Engineering, The Hong Kong Polytechnic University, Hung Hom, Kowloon, Hong Kong (e-mail: eezhaoxu@polyu.edu.hk).

J. Østergaard is with Center for Electric Technology, Department of Electrical Engineering, Technical University of Denmark, DK-2800 Lyngby, Denmark (e-mail: joe@elektro.dtu.dk).

Z. Y. Dong is with the Department of Electrical Engineering, The Hong Kong Polytechnic University, Hung Hom, Kowloon, Hong Kong (e-mail: eezydong@polyu.edu.hk).

K. P. Wong is with the Department of Electrical Engineering, The Hong Kong Polytechnic University, Hung Hom, Kowloon, Hong Kong, and also with the School of Electrical, Electronic, and Computer Engineering, The University of Western Australia, W.A. 6009, Perth, Australia (e-mail: eekpwong@polyu.edu.hk).

Color versions of one or more of the figures in this paper are available online at http://ieeexplore.iee.org.

Digital Object Identifier 10.1109/TEC.2010.2091130 multivariable, nonlinear, and strongly coupled system. Bifurcation phenomena in such a nonlinear system may occur under certain conditions, leading to oscillatory instability. Therefore, practical analysis of DFIG stability will have to involve the bifurcation phenomena. In recent years, some researchers studied stability of industrial motor drives with a wealth of nonlinear dynamics according to the bifurcation and chaos theories [1]-[4]. However, earlier studies mainly deal with dc and simple ac motor drives. The stability analysis of DFIG from a bifurcation perspective is absent.

Eigenvalue analysis of the DFIG wind turbine system has been discussed in [5]-[8], where the participation factor, frequency, and damping ratio analysis are focused. The comprehensive analysis of eigenvalue locus and the eigenvalue sensitivity, which can provide useful guidance in tuning system parameters, have not been carried out earlier.

The Yang et al. have investigated the Hopf bifurcation in a vector-controlled DFIG with one-mass drive train [9]. The main purpose of this paper is to study the oscillatory stability of a DFIG system with respect to varying wind speed, and to analyze the eigenvalue sensitivity as well. A more comprehensive system model, incorporating two-mass drive train, pitch control, etc., is developed. Based on this model, the eigenvalue loci are analyzed, revealing that with inappropriate controller parameters, Hopf bifurcation is likely to happen in the system under certain conditions, such as variation of wind speed. Then, eigenvalue sensitivity analysis is carried out to identify possible sources of instability, as well as the key influential parameters with respect to system oscillatory stability. Furthermore, in order to obtain the overview of system oscillatory stability, Hopf bifurcation boundaries with regard to some key parameters are analyzed, in order to facilitate optimal design of the DFIG wind turbine system. This paper focuses on the small-signal-stability analysis of the DFIG wind turbine system itself. The impact of the DFIG on the power system stability will be considered in our future research.

\section{Modeling OF DFIG Wind TuRbine System FOR OSCILLATORY STABILITY ANALYSIS}

As shown in Fig. 1 [10], the DFIG system utilizes a wound rotor induction generator in which the stator windings are directly connected to the three-phase grid and the rotor windings are fed through three-phase back-to-back bidirectional pulsewidth modulation (PWM) converters. The back-to-back PWM converters consist of two three-phase six-switch converters, i.e., the rotor- and the grid-side converter, between which a dc-link capacitor is placed. For the wind turbine control level, two stage 


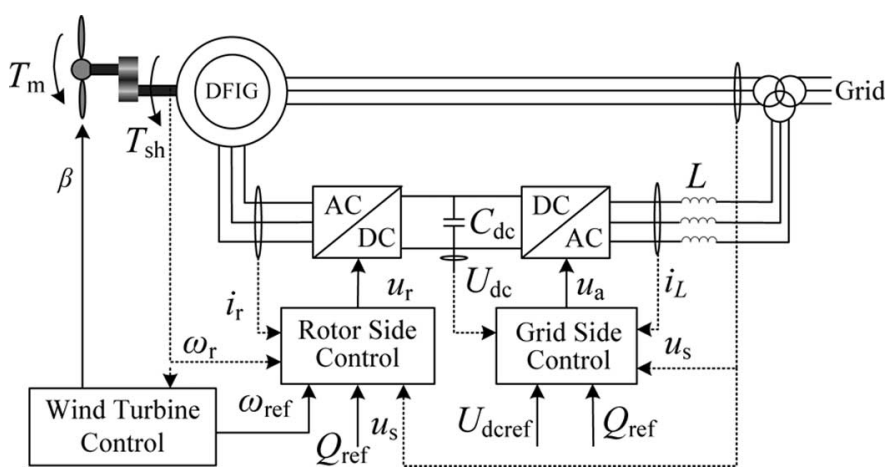

Fig. 1. Schematic diagram of DFIG wind turbine system.

control strategies, based on the electric power versus wind speed curve, are used for DFIG wind turbines: power optimization strategy below rated wind speed and power limitation strategy above rated wind speed [10]. For the DFIG control level, vector control is used for both the rotor- and the grid-side converters to achieve decoupled control of active and reactive power.

It is recognized that the wind power generations involving DFIG often experience different oscillations resulted from the DFIG and its auxiliary systems [9], [11]. In order to study the oscillatory behavior of the system, small-signal-stability analysis, especially the Hopf bifurcation, is needed. The modeling of DFIG has been studied in [5]-[13]; however, there is currently a lack of a systematic comprehensive modeling approach suitable for small-signal stability. In the following section, we develop a comprehensive model for the DFIG wind turbine system. This model particularly enables small-signal-stability analysis of the overall system.

\section{A. Generator}

According to the voltage- and flux-linkage equations of the induction generator [13], [14], the differential equations of the stator and rotor circuits of the induction generator with stator and rotor current as state variables can be given in a $d-q$ reference frame rotating at synchronous speed (we define this reference frame as the generator reference frame in this paper) as follows:

$$
\left\{\begin{aligned}
\frac{d i_{d s}}{d t}= & D\left[R_{s} L_{r} i_{d s}+\left(\omega_{s}-\omega_{r}\right) L_{m}^{2} i_{q s}-\omega_{s} L_{s} L_{r} i_{q s}\right. \\
& \left.-R_{r} L_{m} i_{d r}-\omega_{r} L_{r} L_{m} i_{q r}-L_{r} u_{d s}+L_{m} u_{d r}\right] \\
\frac{d i_{q s}}{d t}= & D\left[-\left(\omega_{s}-\omega_{r}\right) L_{m}^{2} i_{d s}+\omega_{s} L_{s} L_{r} i_{d s}+R_{s} L_{r} i_{q s}\right. \\
& \left.+\omega_{r} L_{r} L_{m} i_{d r}-R_{r} L_{m} i_{q r}-L_{r} u_{q s}+L_{m} u_{q r}\right] \\
\frac{d i_{d r}}{d t}= & D\left[-R_{s} L_{m} i_{d s}+\omega_{r} L_{s} L_{m} i_{q s}+R_{r} L_{s} i_{d r}\right. \\
& \left.+\omega_{s} L_{m}^{2} i_{q r}-\left(\omega_{s}-\omega_{r}\right) L_{s} L_{r} i_{q r}+L_{m} u_{d s}-L_{s} u_{d r}\right] \\
\frac{d i_{q r}}{d t}= & D\left[-\omega_{r} L_{s} L_{m} i_{d s}-R_{s} L_{m} i_{q s}-\omega_{s} L_{m}^{2} i_{d r}\right. \\
& \left.+\left(\omega_{s}-\omega_{r}\right) L_{s} L_{r} i_{d r}+R_{r} L_{s} i_{q r}+L_{m} u_{q s}-L_{s} u_{q r}\right]
\end{aligned}\right.
$$

where $\mathbf{i}_{s}=i_{d s}+j i_{q s}$ and $\mathbf{i}_{r}=i_{d r}+j i_{q r}$ are the stator and rotor current vectors, respectively; $\mathbf{u}_{s}=u_{d s}+j u_{q s}$ and $\mathbf{u}_{r}=$ $u_{d r}+j u_{q r}$ are the stator and rotor voltage vectors, respectively; $D=\omega_{b} /\left(L_{m}{ }^{2}-L_{s} L_{r}\right)$. This paper adopts the motor convention meaning that stator and rotor currents are positive when flowing into the generator. The quantities in the system model are in per unit except the time $t$.

\section{B. Drive Train}

When studying the stability of DFIG wind turbine, the twomass model of the drive train is important, as the wind turbine shaft is relatively softer than the typical steam turbine shaft in conventional power plants [15]. The equations, which represent the two-mass model of the drive train, are expressed as follows:

$$
\begin{aligned}
\frac{d \omega_{r}}{d t} & =\frac{1}{2 H_{g}}\left(T_{\mathrm{sh}}-T_{e}-B \omega_{r}\right) \\
\frac{d \theta_{t}}{d t} & =\omega_{b}\left(\omega_{t}-\omega_{r}\right) \\
\frac{d \omega_{t}}{d t} & =\frac{1}{2 H_{t}}\left(T_{m}-T_{\mathrm{sh}}\right)
\end{aligned}
$$

where $\omega_{b}, \omega_{r}$, and $\omega_{t}$ are the base, generator, and wind turbine speeds, respectively. $H_{g}$ and $H_{t}$ [SI unit(s)] are the generator and turbine inertias, respectively. $\theta_{t}$ is the shaft twist angle. The electromagnetic torque $T_{e}$, the shaft torque $T_{\mathrm{sh}}$, and the mechanical torque $T_{m}$, which are the power input of the wind turbine, are as follows:

$$
\begin{aligned}
T_{e} & =L_{m}\left(i_{d s} i_{q r}-i_{q s} i_{d r}\right) \\
T_{\mathrm{sh}} & =K_{\mathrm{sh}} \theta_{t}+D_{\mathrm{sh}} \omega_{b}\left(\omega_{t}-\omega_{r}\right) \\
T_{m} & =\frac{0.5 \rho \pi R^{2} C_{p}(\lambda, \beta) V_{w}^{3}}{\omega_{t}}
\end{aligned}
$$

where $C_{p}$ is the power coefficient as follows:

$$
\begin{aligned}
C_{p} & =0.22\left(\frac{116}{\lambda_{\mathrm{i}}}-0.4 \beta-5\right) e^{-12.5 / \lambda_{i}} \\
\lambda_{i} & =\frac{1}{1 /(\lambda+0.08 \beta)-0.035 /\left(\beta^{3}+1\right)}
\end{aligned}
$$

where $\lambda=\omega_{t} R / V_{w}$ is the blade tip speed ratio. $C_{p}(\lambda, \beta)$ has a maximum $C_{p}^{\max }$ for a particular tip speed ratio $\lambda_{\text {opt }}$ and pitch angle $\beta_{\mathrm{opt}}$. The aim for variable wind turbine at wind speeds lower than rated value is to adjust the rotor speed at varying wind speeds; therefore, $\lambda$ and $C_{p}$ are always maintained at the optimal and maximum value, respectively. The speed control of the DFIG is achieved by driving the generator speed along the optimum power-speed characteristic curve [10], which corresponds to the maximum energy capture from the wind. In this curve, when generator speed is less than the low limit or higher than the rated value, the reference speed is set to the minimal value or rated value, respectively. When generator speed is between the lower limit and the rated value, the rotor speed reference can be obtained by substituting $\lambda=\omega_{t} R / V_{w}$ into (7) as follows:

$$
\omega_{\mathrm{ref}}=\sqrt{\frac{T_{m}}{K_{\mathrm{opt}}}}
$$




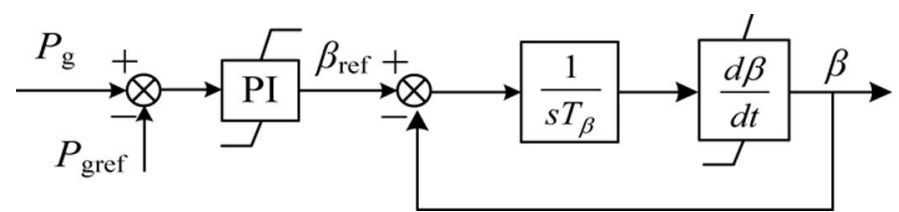

Fig. 2. Schematic diagrasm of the pitch control.

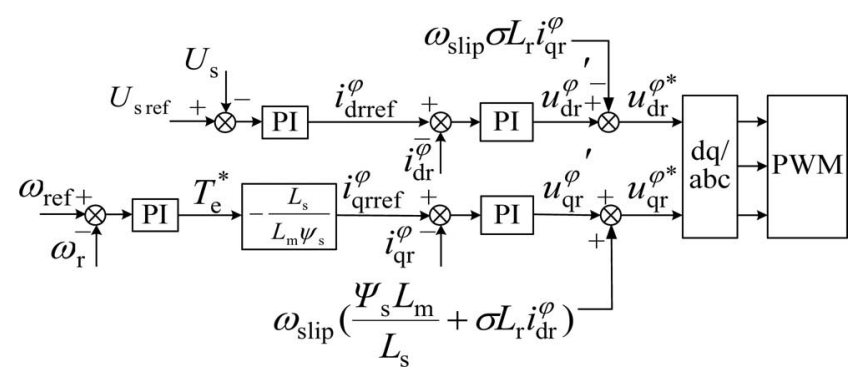

Fig. 3. Control scheme of the rotor-side converter.

where $K_{\mathrm{opt}}=\frac{\rho \pi R^{5} C_{p}^{\max }}{2 \lambda_{\mathrm{opt}}^{3}}$ is the optimal constant of wind turbine. Equation (10) is an easy and direct way to get $\omega_{\text {ref }}$ from the academic perspective while it implies the mechanical torque observer is needed. Although mechanical torque observation is not popularly used in industrial application, due to some engineering problems, it is available in practice and can obtain improved optimum operating point tracking [16], [17].

\section{Pitch Control}

The pitch angle of the blade is controlled to optimize the power extraction of wind turbine as well as to prevent overrated power production in strong wind. The pitch servo is modeled as follows:

$$
\frac{d \beta}{d t}=\frac{1}{T_{\beta}}\left(\beta_{\text {ref }}-\beta\right) .
$$

For the sake of simplicity, the reference of the pitch angle $\beta_{\text {ref }}$ is kept zero when wind speed is below rated value. When wind speed is higher than rated value, the power limitation is active by adjusting the pitch angle using the pitch-control scheme shown in Fig. 2 [10], and

$$
\left\{\begin{array}{l}
\beta_{\text {ref }}=K_{P \beta}\left(P_{g}-P_{\text {ref }}\right)+x_{\beta} \\
\dot{x}_{\beta}=\frac{K_{P \beta}}{T_{I \beta}}\left(P_{g}-P_{\text {ref }}\right) .
\end{array}\right.
$$

\section{Rotor-Side Converter}

The generic control scheme of the rotor-side converter is illustrated in Fig. 3. In order to decouple the electromagnetic torque and the rotor excitation current, the induction generator is controlled in the stator-flux-oriented reference frame, which is a synchronously rotating reference frame, with its $d$-axis oriented along the stator-flux vector position [17]. The typical proportional-integral (PI) controllers are used for regulation in both the rotor speed and the terminal voltage (outer) control loop

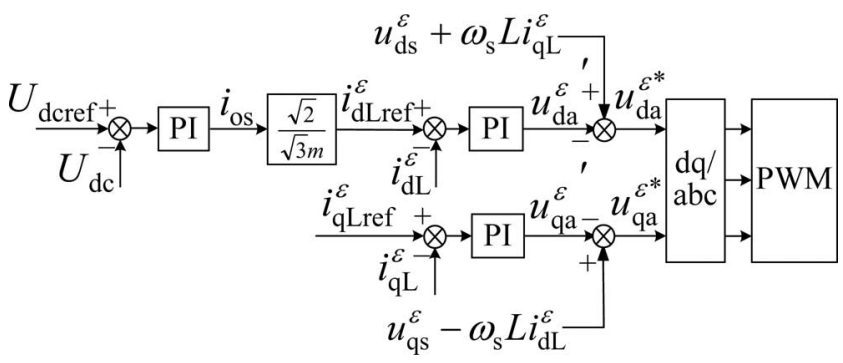

Fig. 4. Control scheme of the grid-side converter.

and the rotor current (inner) control loop. In Fig. 3, superscript $\varphi$ denotes the variable is in the stator-flux-oriented reference frame.

Based on the stator-flux orientation, the stator flux can be described as $\psi_{d s}^{\varphi}=\Psi_{s}$ and $\psi_{q s}^{\varphi}=0$ [17]. Accordingly, the rotorvoltage equations can be expressed as follows:

$$
\left\{\begin{array}{l}
u_{d r}^{\varphi}=R_{r} i_{d r}^{\varphi}-\sigma L_{r} i_{q r}^{\varphi}\left(\omega_{s}-\omega_{r}\right)+\frac{\sigma L_{r}}{\omega_{b}} \frac{d i_{d r}^{\varphi}}{d t} \\
u_{q r}^{\varphi}=R_{r} i_{q r}^{\varphi}+\left(\sigma L_{r} i_{d r}^{\varphi}+\frac{L_{m}}{L_{s}} \Psi_{s}\right)\left(\omega_{s}-\omega_{r}\right)+\frac{\sigma L_{r}}{\omega_{b}} \frac{d i_{q r}^{\varphi}}{d t}
\end{array}\right.
$$

where $\sigma=1-\left(L_{m}^{2} / L_{s} L_{r}\right)$ is the leakage factor.

Usually, the bandwidth of the inner current-control loop is much wider than the outer speed-control loop [17]. Hence, the fast dynamics of the current-control loop does not affect the low-frequency oscillations. On account of this, we assume that the rotor current can well track the reference current, and thus, omit the dynamics of the rotor current-control loop. Under this assumption and according to the control scheme of the rotorside converter shown in Fig. 3, the equations with respect to the control of the rotor-side converter become

$$
\left\{\begin{array}{l}
\dot{x}_{\omega}=\frac{K_{P \omega}}{T_{I \omega}}\left(\omega_{\text {ref }}-\omega_{r}\right) \\
\dot{x}_{u s}=\frac{K_{P u s}}{T_{I u s}}\left(U_{s \mathrm{ref}}-U_{s}\right) \\
i_{d r}^{\varphi}=i_{d r \mathrm{ref}}^{\varphi}=K_{P u s}\left(U_{s \mathrm{ref}}-U_{s}\right)+x_{u s} \\
i_{q r}^{\varphi}=i_{q r \mathrm{ref}}^{\varphi}=-\frac{L_{s}}{L_{m} \Psi_{s}}\left[K_{P \omega}\left(\omega_{\mathrm{ref}}-\omega_{r}\right)+x_{\omega}\right]
\end{array}\right.
$$

where $K_{P \omega}$ and $T_{I \omega}$ are the proportional gain and the integral time constant of the rotor-speed controller, respectively.

The rotor voltage in the generator reference frame can be derived by the following: [18]

$$
\left[\begin{array}{l}
u_{d r} \\
u_{q r}
\end{array}\right]=\left[\begin{array}{cc}
\cos \varphi & -\sin \varphi \\
\sin \varphi & \cos \varphi
\end{array}\right]\left[\begin{array}{l}
u_{d r}^{\varphi} \\
u_{q r}^{\varphi}
\end{array}\right]
$$

where $\varphi=\arctan \left(\psi_{q s} / \psi_{d s}\right)$ is the angle between the statorflux vector and the $d$-axis of the generator reference frame.

\section{E. Grid-Side Converter}

Fig. 4 shows the control scheme of the grid-side converter. In order to obtain the independent control of active and reactive power flowing between the grid and the grid-side converter, the 
converter control operates in the grid-voltage-oriented reference frame, which is a synchronously rotating reference frame, with its $d$-axis oriented along the grid-voltage vector position [17]. Similarly, the typical PI controllers are used for regulation in both dc-link voltage (outer) control loop and grid-side inductor current (inner) control loop. In Fig. 4, superscript $\varepsilon$ denotes the variable is in the grid-voltage-oriented reference frame.

Under the grid-voltage-oriented reference frame, the equations of the grid-side converter are given by [17] the following:

$$
\left\{\begin{array}{l}
u_{d s}^{\varepsilon}=U_{s}=R_{L} i_{d L}^{\varepsilon}+\frac{L}{\omega_{b}} \frac{d i_{d L}^{\varepsilon}}{d t}-\omega_{s} L i_{q L}^{\varepsilon}+u_{d a}^{\varepsilon} \\
u_{q s}^{\varepsilon}=0=R_{L} i_{q L}^{\varepsilon}+\frac{L}{\omega_{b}} \frac{d i_{q L}^{\varepsilon}}{d t}+\omega_{s} L i_{d L}^{\varepsilon}+u_{q a}^{\varepsilon}
\end{array}\right.
$$

where $\mathbf{i}_{L}=i_{d L}+j i_{q L}$ is the grid-side-inductor-current vector, and $\mathbf{u}_{a}=u_{d a}+j u_{q a}$ is the grid-side converter voltage vector.

Similar to the derivation of the rotor-side controller, based on the same simplification, which omits the fast dynamics in the inner current-control loop, and according to the control scheme of the grid-side converter shown in Fig. 4, the equations with respect to the control of the grid-side converter are described as follows:

$$
\left\{\begin{array}{l}
\dot{x}_{v}=\frac{K_{P v}}{T_{I v}}\left(U_{\mathrm{dcref}}-U_{\mathrm{dc}}\right) \\
i_{q L}^{\varepsilon}=I_{q L \text { ref }} \\
i_{d L}^{\varepsilon}=i_{d L \text { ref }}^{\varepsilon}=\frac{\sqrt{2}}{\sqrt{3} m}\left[K_{P v}\left(U_{\mathrm{dcref}}-U_{\mathrm{dc}}\right)+x_{u}\right]
\end{array}\right.
$$

where $K_{P v}$ and $T_{I v}$ are the proportional gain and the integral time constant of the dc-link voltage controller, respectively.

The relationship between the generator reference frame and the grid-voltage-oriented reference frame can be given by [18] the following:

$$
\left[\begin{array}{c}
V_{d a} \\
V_{q a}
\end{array}\right]=\left[\begin{array}{cc}
\cos \varepsilon & -\sin \varepsilon \\
\sin \varepsilon & \cos \varepsilon
\end{array}\right]\left[\begin{array}{c}
V_{d a}^{\varepsilon} \\
V_{q a}^{\varepsilon}
\end{array}\right]
$$

where $\varepsilon=\arctan \left(u_{q s} / u_{d s}\right)$ is the angle between the gridvoltage vector and the $d$-axis of the generator reference frame; $V$ can be the variable of voltage $u$ or current $i$.

\section{F. DC-link Capacitor}

The equation, which describes the energy balance of the dclink capacitor can be expressed as follows:

$$
\begin{aligned}
\frac{C_{\mathrm{dc}} U_{\mathrm{dc}}}{\omega_{b}} \frac{d U_{\mathrm{dc}}}{d t} & =p_{a}-p_{r} \\
& =\frac{3}{2}\left(u_{d a} i_{d L}+u_{q a} i_{q L}-u_{d r} i_{d r}-u_{q r} i_{q r}\right)
\end{aligned}
$$

where $U_{\mathrm{dc}}$ is the dc-link voltage, and $p_{a}$ and $p_{r}$ are the powers supplied to the grid-side converter and the rotor circuit, respectively.

From (1)-(19), we can obtain a set of state equations to present the DFIG wind turbine system. They can be written in a compact form as follows:

$$
\dot{\mathbf{x}}=f(\mathbf{x}, \mathbf{u})
$$

where $\mathbf{x}$ and $\mathbf{u}$ are the vectors with respect to the state and the input variables, which are defined as $\mathbf{x}=\left[\begin{array}{llllll}i_{d s} & i_{q s} & i_{d r} & i_{q r} & \omega_{r} & U_{\mathrm{dc}}\end{array}\right.$

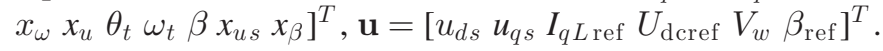

\section{SMALl-Signal-Stability ANALYSIS}

A DFIG wind turbine system, modeled by (1)-(19) or simply (20), can be linearized to form the linear model around an equilibrium point for small-signal-stability analysis.

\section{A. System Jacobian}

The Jacobian matrix is of great importance to stability analysis of dynamical systems. In order to analyze the Jacobian matrix, the equilibrium point $X_{0}$ of the system needs to be calculated by solving equation $f(x, u)=0$. With $X_{0}$, the Jacobian matrix of the system evaluated at the equilibrium point is given in (21), shown at the bottom of this page, where $\left\{J_{i, j}\right\}(i=$

$J\left(X_{0}\right)=\mathbf{A}=\left.\frac{\partial f}{\partial x}\right|_{x=X_{0}}=\left[\begin{array}{cccccccccccccc}J_{11} & J_{12} & J_{13} & J_{14} & J_{15} & 0 & J_{17} & 0 & J_{19} & J_{110} & J_{111} & J_{112} & 0 \\ J_{21} & J_{22} & J_{23} & J_{24} & J_{25} & 0 & J_{27} & 0 & J_{29} & J_{210} & J_{211} & J_{212} & 0 \\ J_{31} & J_{32} & J_{33} & J_{34} & J_{35} & 0 & J_{37} & 0 & J_{39} & J_{310} & J_{311} & J_{312} & 0 \\ J_{41} & J_{42} & J_{43} & J_{44} & J_{45} & 0 & J_{47} & 0 & J_{49} & J_{410} & J_{411} & J_{412} & 0 \\ J_{51} & J_{52} & J_{53} & J_{54} & J_{55} & 0 & 0 & 0 & J_{59} & J_{510} & 0 & 0 & 0 \\ J_{61} & J_{62} & J_{63} & J_{64} & J_{65} & J_{66} & J_{67} & J_{68} & J_{69} & J_{610} & J_{611} & J_{612} & 0 \\ 0 & 0 & 0 & 0 & J_{75} & 0 & 0 & 0 & 0 & J_{710} & J_{711} & 0 & 0 \\ 0 & 0 & 0 & 0 & 0 & J_{86} & 0 & 0 & 0 & 0 & 0 & 0 & 0 \\ 0 & 0 & 0 & 0 & J_{95} & 0 & 0 & 0 & 0 & J_{910} & 0 & 0 & 0 \\ 0 & 0 & 0 & 0 & J_{105} & 0 & 0 & 0 & J_{109} & J_{1010} & J_{1011} & 0 & 0 \\ J_{1101} & J_{1102} & 0 & 0 & 0 & J_{116} & 0 & J_{118} & 0 & 0 & J_{1111} & 0 & J_{1113} \\ 0 & 0 & 0 & 0 & 0 & 0 & 0 & 0 & 0 & 0 & 0 & 0 & 0 \\ J_{131} & J_{132} & 0 & 0 & 0 & J_{136} & 0 & J_{138} & 0 & 0 & 0 & 0 & 0\end{array}\right]$


$1,2, \ldots, 4$ and $j=1,2, \ldots, 13)$ represents the linearized dynamics of the generator from $(1) ;\left\{J_{i, j}\right\}(i=5,9,10$ and $j$ $=1,2, \ldots, 13)$ represents the linearized dynamics of the drive train from (2)-(4); $\left\{J_{i, j}\right\}(i=6,7,8,12$ and $j=1,2, \ldots, 13)$ represents the linearized dynamics of the dc-link capacitor and controllers of the back-to-back converters from (14), (17), and (19); $\left\{J_{i, j}\right\}(i=11,13$ and $j=1,2, \ldots, 13)$ represents the linearized dynamics of the pitch control from (11) and (12). The elements of the Jacobian matrix are given in the Appendix.

In this paper, we focus on the oscillatory stability analysis of the DFIG itself, the studied DFIG is directly connected to the infinite bus and the dynamic behavior of the grid is not concerned. Therefore, in (14), we have $U_{s}=U_{s \text { ref }}$, and the differential equation associated with the voltage-control loop can be omitted. Under this assumption, 12th row and 12th column of the Jacobian matrix can be removed. When wind speed is lower than the rated value, the power limitation is not active; therefore, 13th row and 13th column of matrix $J\left(X_{0}\right)$, which are associated with pitch-control loop, can be deleted.

\section{B. Hopf Bifurcation}

This paper concentrates on the analysis of local bifurcations, particularly Hopf bifurcation that can occur in a DFIG system.

Hopf bifurcation corresponds to emergence of a periodic solution from an equilibrium point of (20); in this way, the HFB is responsible for system oscillatory behavior. According to the Hopf bifurcation theorem [19], a HFB can be supercritical or subcritical. A supercritical HFB has the initially stable periodic solution branch and will result in a smooth transition to oscillations. On the other hand, a subcritical HFB is associated with an unstable periodic solution branch and will lead to a hard transition to large amplitude oscillations.

The DFIG wind turbine system works in power-optimization operation mode at most of the time. Under this operation mode, the rotor speed of DFIG usually changes along with the variation of wind speed [10]. We will consequently focus on the effect of the variation of wind speed as well as rotor speed on the dynamical behavior of DFIG under the power optimization operation mode in the following section.

\section{Eigenvalue Sensitivity}

Eigenvalue sensitivity, defined as the rate and direction of eigenvalue movement in the $s$-plane due to the variation in system parameters is an efficient tool for designing the control system and parameterizing the system, especially for the higher order systems. Two types of eigenvalue sensitivities are studied: eigenvalue sensitivity with respect to the entry of system state matrix and system parameter.

The participation factor is a special group of eigenvalue sensitivity with respect to the system states [20] as follows:

$$
P_{k i}=\frac{\partial \lambda_{i}}{\partial a_{k k}}=u_{k i} v_{k i}(i, k=1,2, \ldots, n)
$$

where $a_{k k}$ is the $k$ th row and $k$ th column of $\mathbf{A}, u_{i}, v_{i} \in R^{n}$ denote the normalized right and left eigenvectors corresponding to $\lambda_{i}$, respectively.
TABLE I

SYSTEM PARAMETERS USED IN SIMULATIONS

\begin{tabular}{ccc}
\hline \hline Parameters & Descriptions & Values \\
\hline$R_{\mathrm{s}}, L_{\mathrm{ls}}$ & Stator resistance and leakage inductance & $0.0076 \mathrm{p} . \mathrm{u} ., 0.171$ \\
$R_{\mathrm{r}}, L_{\mathrm{lr}}$ & Rotor resistance and leakage inductance & $0.005 \mathrm{p} . \mathrm{u} ., 0.156 \mathrm{p} . \mathrm{u}$. \\
$L_{\mathrm{m}}$, & Stator and rotor mutual inductance & $3.5 \mathrm{p} . \mathrm{u}$. \\
$n_{\mathrm{p}}$ & Number of pole pairs & 3 \\
$U_{\mathrm{s}}$ & Peak amplitude of stator voltage & $1 \mathrm{p} . \mathrm{u}$. \\
$\omega_{\mathrm{s}}$ & Stator angular frequency & $1 \mathrm{p} . \mathrm{u}$. \\
$H_{\mathrm{g}}$ & Inertia constant of generator & $0.5 \mathrm{~s}$ \\
$B$ & Friction coefficient of generator & $0.01 \mathrm{p} . \mathrm{u}$. \\
$H_{\mathrm{t}}$ & Inertia constant of wind turbine & $4 \mathrm{~s}$ \\
$K_{\mathrm{opt}}$ & Optimal constant of wind turbine & 0.579 \\
$T_{\beta}$ & Time constant of the pitch servo & $0.25 \mathrm{~s}$ \\
$f_{\mathrm{switch}}$ & Switching frequency of the PWM converters & $2 \mathrm{kHz}$ \\
$C_{\mathrm{dc}}$ & DC-link capacitance & $0.06 \mathrm{~F}$ \\
$R_{L}, L$ & Resistance and inductance of grid side & $0.003 \mathrm{p} . \mathrm{u} ., 0.3 \mathrm{p} . \mathrm{u}$. \\
$U_{\mathrm{dcref}}$ & inductor & $1200 \mathrm{~V}$ \\
$P_{\mathrm{rated}}$ & DC-link voltage reference & $1.5 \mathrm{MW}$ \\
$\omega_{\text {rated }}$ & Rated power & $1.1 \mathrm{p} . \mathrm{u}$. \\
$V_{\mathrm{wrated}}$ & Rated rotor speed of generator & $12 \mathrm{~m} / \mathrm{s}$ \\
$\omega_{\mathrm{b}}$ & Rated wind speed & $314 \mathrm{rad} / \mathrm{s}$ \\
$S_{\mathrm{b}}$ & Base angular frequency & $1.5 \mathrm{MW}$ \\
$U_{\mathrm{b}}$ & Base power & $575 \mathrm{~V}$ \\
\hline \hline
\end{tabular}

TABLE II

Eigenvalues of DFIG Wind Turbine System $\left(V_{w}=12 \mathrm{M} / \mathrm{s}, K_{P \omega}=1\right)$

\begin{tabular}{ccccc}
\hline \hline & $\lambda_{1,2}$ & $\lambda_{3,4}$ & $\lambda_{5,6}$ & $\lambda_{7,8}$ \\
\hline$\lambda=\sigma+j \omega$ & $-6.84 \pm j 314.0$ & $-2.76 \pm j 58.8$ & $-5.47 \pm j 29.4 \mathrm{i}$ & $-0.164 \pm j 1.43$ \\
\hline$\lambda_{9}$ & $\lambda_{10}$ & $\lambda_{11}$ & \\
\hline$\lambda=\sigma+j \omega$ & -34.1 & -14.1 & -4.00 & \\
\hline \hline
\end{tabular}

The first-order sensitivity of an eigenvalue $\lambda_{i}$ with regard to a system-operating parameter $\alpha$ can be given by the following:

$$
\frac{\partial \lambda_{i}}{\partial \alpha}=\frac{u_{i}^{T}(\partial \mathbf{A} / \partial \alpha) v_{i}}{u_{i}^{T} v_{i}} .
$$

The magnitude and the sign of the real part of the eigenvalue sensitivity $S_{\alpha}^{\lambda, \sigma}$ are defined as the size and direction of movement of eigenvalue $\lambda_{i}$ in the horizontal direction in the $s$-plane due to the small perturbation of a general parameter $\alpha$, respectively, whereas the imaginary part of the eigenvalue sensitivity $S_{\alpha}^{\lambda, \omega}$ are associated with the movement of eigenvalue $\lambda_{i}$ in the vertical direction.

\section{Theoretical System Eigenvalue Analysis}

Using the Jacobian matrix derived in Section III, eigenvalue analysis of the DFIG wind turbine system is given in this section.

\section{A. Eigenvalue Loci}

The system parameters, set as the standard value from MATLAB vR2007b Demo, are detailed in Table I. Using the Jacobian matrix (21), eigenvalues of the DFIG system can be calculated. All the eigenvalues at rated wind speed $\left(V_{w}=12 \mathrm{~m} / \mathrm{s}, \omega_{r}=\right.$ 1.1 p.u., $K_{P \omega}=1$ ) are listed in Table II. The eigenvalue loci of corresponding oscillatory modes are plotted in Figs. 5 and 6.

Fig. 5(a)-(d) shows the eigenvalue loci of $\lambda_{1,2}, \lambda_{3,4}, \lambda_{5,6}$, and $\lambda_{7,8}$ as wind speed increases when $K_{P \omega}=60$. The arrows in 


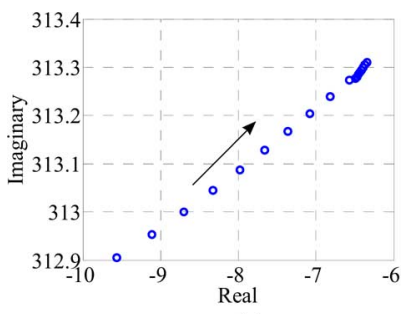

(a)

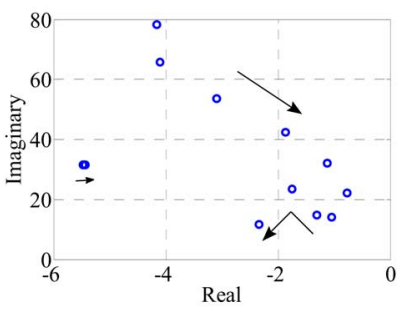

(c)

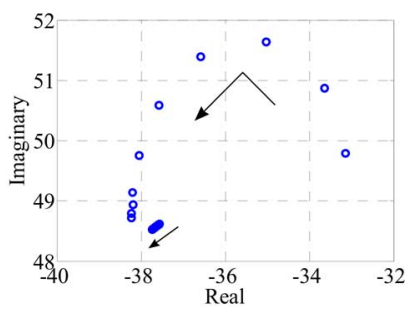

(b)

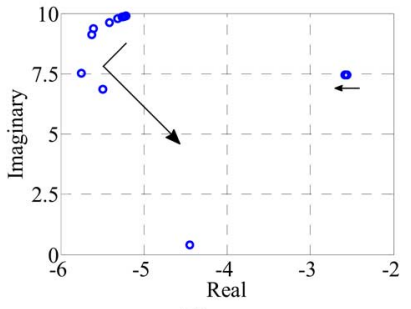

(d)
Fig. 5. Eigenvalue loci as wind speed increases from 8 to $15 \mathrm{~m} / \mathrm{s}$ ( $K_{P \omega}=$ 60) for (a) $\lambda_{1,2}$, (b) $\lambda_{3,4}$, (c) $\lambda_{5,6}$, and (d) $\lambda_{7,8}$.

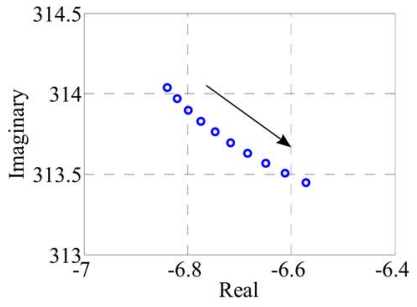

(a)

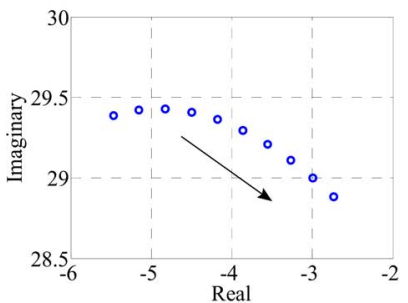

(c)

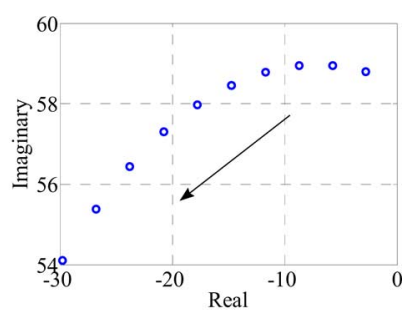

(b)

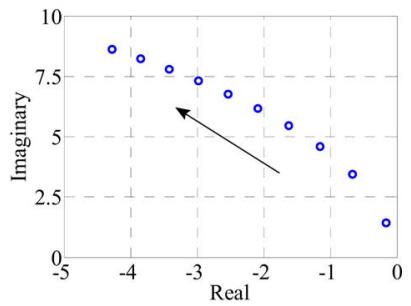

(d)
Fig. 6. Eigenvalue loci as the proportional gain of rotor speed controller $K_{P \omega}$ increases from 1 to $50\left(V_{w}=12 \mathrm{~m} / \mathrm{s}\right)$ for (a) $\lambda_{1,2}$, (b) $\lambda_{3,4}$, (c) $\lambda_{5,6}$, and (d) $\lambda_{7,8}$.

the figures indicate the directions of the eigenvalue movement as $V_{w}$ increases from 8 to $15 \mathrm{~m} / \mathrm{s}$. When $V_{w}$ is higher than the rated value, the power and generator speed limitation are activated, resulting in slower movement of all the eigenvalues. As shown in this figure, $\lambda_{1,2}$ move to the imaginary axis and the oscillation frequency is increased as $V_{w}$ increases. For $\lambda_{3,4}$, they move away from the imaginary axis. The oscillation frequency increases up to a point $\left(V_{w}=9 \mathrm{~m} / \mathrm{s}\right)$, then decreases again. For $\lambda_{5,6}$, they move to right and the oscillation frequency decreases up to a point ( $V_{w}=10.2 \mathrm{~m} / \mathrm{s}$ ), then suddenly moves toward left. When $V_{w}$ is higher than the rated value, they move to right from a new position, which is far away from imaginary axis. For $\lambda_{7,8}$, they move to left up to a point $\left(V_{w}=11 \mathrm{~m} / \mathrm{s}\right)$, then they move toward right. The oscillation frequency is decreased as $V_{w}$ increases. When $V_{w}$ is higher than the rated value, they move to left from a new position close to imaginary axis.
TABLE III

EIGENVALUES FOR VARIATION VALUE OF $V_{w}$ AND $\omega_{r}\left(K_{P \omega}=70\right)$

\begin{tabular}{|c|c|c|c|}
\hline$V_{\mathrm{w}}$ (p.u.) & $\omega_{\mathrm{r}}$ (p.u.) & Eigenvalues & Remarks \\
\hline 0.957 & 0.959 & $\begin{array}{c}-7.11 \pm j 312.8,-57.0 \pm j 28.5, \mathbf{0 . 0 0 6 6} \pm j 16.7 \\
-6.79 \pm j 7.93,-34.2,-14.1,-4.00\end{array}$ & Unstable \\
\hline 0.9568 & 0.9593 & $\begin{array}{c}-7.11 \pm j 312.8,-57.0 \pm j 28.5,0 \pm j 16.7 \\
-6.78 \pm j 7.92,-34.2,-14.1,-4.00\end{array}$ & $\begin{array}{c}\text { Hopf } \\
\text { bifurcation }\end{array}$ \\
\hline 0.959 & 0.962 & $\begin{array}{c}-7.09 \pm j 312.8,-57.0 \pm j 28.5,-\mathbf{0 . 1 4} \pm j \mathbf{1 6 . 3} \\
\quad-6.62 \pm j 7.65,-34.2,-14.1,-4.00\end{array}$ & Stable \\
\hline 1.018 & 1.02 & $\begin{array}{l}-6.65 \pm j 312.9,-57.3 \pm j 27.6,-\mathbf{1 . 6 1} \pm j \mathbf{1 4 . 5} \\
\quad-5.29 \pm j 4.80,-34.2,-14.1,-4.00\end{array}$ & Stable \\
\hline 1.046 & 1.048 & $\begin{array}{l}-6.45 \pm j 313.0,-56.9 \pm j 27.1,-\mathbf{0 . 1 2} \pm j \mathbf{1 7 . 9} \\
\quad-7.36 \pm j 8.73,-34.1,-14.1,-4.00\end{array}$ & Stable \\
\hline 1.0536 & 1.0564 & $\begin{array}{c}-6.40 \pm j 313.0,-56.7 \pm j 27.0,0 \pm j \mathbf{1 9 . 4} \\
-7.71 \pm j 9.45,-34.1,-14.1,-4.000\end{array}$ & $\begin{array}{c}\text { Hopf } \\
\text { bifurcation }\end{array}$ \\
\hline 1.056 & 1.06 & $\begin{array}{c}-6.39 \pm j 313.0,-56.7 \pm j 27.0, \mathbf{0 . 0 0 3 8} \pm j \mathbf{j 1 9 . 6} \\
-7.75 \pm j 9.53,-34.1,-14.1,-4.00\end{array}$ & Unstable \\
\hline
\end{tabular}

Fig. 6(a)-(d) shows the eigenvalue loci of $\lambda_{1,2}, \lambda_{3,4}, \lambda_{5,6}$ and $\lambda_{7,8}$ as the proportional gain of rotor speed controller $K_{P \omega}$ increases from 1 to 50 , respectively. $\lambda_{1,2}$ and $\lambda_{5.6}$ move toward the imaginary axis, while $\lambda_{3,4}$ and $\lambda_{7,8}$ move away from the imaginary axis as $K_{P \omega}$ increases. The oscillation frequencies of $\lambda_{1,2}, \lambda_{3,4}$, and $\lambda_{5,6}$ are decreased, while the oscillation frequency of $\lambda_{7,8}$ is increased as $K_{P \omega}$ increases.

The aforementioned analyses show that the operation stability of a DFIG wind turbine system can vary very much due to reasons, such as varying wind speed and control parameters. For the studied wind turbine, it is observed that as wind speed varies, $\lambda_{1,2}$ and $\lambda_{5,6}$ tend to move to the right half of the $s$ plane, if $K_{P \omega}$ is inappropriately selected above a critical value. This indicates that they are the key modes for inducing the oscillatory instability, especially when wind speed is lower than rated value. Moreover, it is obvious from the results in Fig. 5 that the system is more stable and oscillation can hardly happen when the wind speed is higher than the rated value due to activeness of the power limitation. Therefore, the oscillatory instability and eigenvalue sensitivity at higher wind speed will not been analyzed in the following section.

\section{B. Hopf Bifurcation}

Table III shows the effect of $V_{w}$ and $\omega_{r}$ variations on the eigenvalues of the studied system when $K_{P \omega}$ is set improperly $\left(K_{P \omega}=70\right)$. It shows that there totally exist four pairs of complex conjugate eigenvalues and two real eigenvalues, as $V_{w}$ and $\omega_{r}$ vary. When $\omega_{r}$ is around the synchronous speed, all these eigenvalues have negative real parts. As $\omega_{r}$ increases at a critical value $\left(\omega_{r}=1.0564\right.$ p.u. $)$, a simple pair of pure imaginary eigenvalues $\lambda_{5,6}=0 \pm j 19.4$ of around $3 \mathrm{~Hz}$ appears, while other eigenvalues remain in the left half plane, and $\left.((d(\operatorname{Re}[\lambda(\mu)])) / d \mu)\right|_{\mu *}<0$.

A supercritical HFB, therefore, occurs and a stable limit cycle emerges, leading to a smooth transition to time-periodic oscillations in the studied DFIG [19]. As $\omega_{r}$ increases further, the real part of the complex eigenvalues changes to positive, so the system loses stability and oscillates periodically. When $\omega_{r}$ decreases at a critical value $\left(\omega_{r}=0.9593\right.$ p.u. $)$, a simple pair of pure imaginary eigenvalues $\lambda_{5,6}=0 \pm j 16.7$ of around $3 \mathrm{~Hz}$ appears, while other eigenvalues remain in the left-half 
TABLE IV

EIGENVALUES AND PARTICIPATION FACTORS $\left(V_{w}=12 \mathrm{~m} / \mathrm{s}, K_{P \omega}=1\right)$

\begin{tabular}{ccc}
\hline \hline & Eigenvalue & Participation factors $(\%)$ \\
\hline$\lambda_{1,2}$ & $-6.84 \pm j 314.0$ & $P i_{\mathrm{ds}}=26 \%, P i_{\mathrm{qs}}=26 \%, P i_{\mathrm{dr}}=24 \%, P i_{\mathrm{qr}}=24 \%$ \\
$\lambda_{3,4}$ & $-2.76 \pm j 58.8$ & $P i_{\mathrm{ds}}=10 \%, P i_{\mathrm{dr}}=11 \%, P \omega_{\mathrm{r}}=36 \%, P \theta_{\mathrm{t}}=39 \%$ \\
$\lambda_{5,6}$ & $-5.47 \pm j 29.4 \mathrm{i}$ & $P i_{\mathrm{ds}}=24 \%, P i_{\mathrm{qs}}=24 \%, P i_{\mathrm{dr}}=26 \%, P i_{\mathrm{qr}}=26 \%$ \\
$\lambda_{7,8}$ & $-0.164 \pm j 1.43$ & $P x_{\omega}=46 \%, P \omega_{\mathrm{t}}=42 \%$ \\
$\lambda_{9}$ & -34.1 & $P U_{\mathrm{dc}}=71 \%, P x_{\mathrm{u}}=29 \%$ \\
$\lambda_{10}$ & -14.1 & $P U_{\mathrm{dc}}=29 \%, P x_{\mathrm{u}}=71 \%$ \\
$\lambda_{11}$ & -4.00 & $P \beta=100 \%$ \\
\hline \hline
\end{tabular}

plane, and $\left.((d(\operatorname{Re}[\lambda(\mu)]) / d \mu))\right|_{\mu *}<0$. Therefore, a supercritical HFB occurs. As $\omega_{r}$ decreases further, the real part of the complex eigenvalues changes to positive and the system loses stability with periodical oscillation.

The analysis reveals that the Hopf bifurcation can happen in a DFIG wind turbine with inappropriate tuning of control parameters. For this studied system, this is essentially caused by the shift of the real part of $\lambda_{5,6}$ from negative to zero.

\section{Eigenvalue Sensitivity}

The eigenvalues and participation factors of the studied system when $\omega_{r}=1.1$ p.u. $\left(V_{w}=12 \mathrm{~m} / \mathrm{s}, K_{P \omega}=1\right)$ are shown in Table IV. We can see that $\lambda_{1,2}$ are associated with the stator flux; $\lambda_{3,4}$ are associated with the rotor and turbine mechanical; $\lambda_{5,6}$ are associated with the rotor flux; $\lambda_{7,8}$ are associated with rotor and turbine mechanical; $\lambda_{9}$ and $\lambda_{10}$ are associated with dc-link voltage; $\lambda_{11}$ is associated with dynamics of pitch angle. The first-order eigenvalue sensitivities with respect to some machine and control parameters at different rotor speeds are listed in Table V. As the required perturbed parameters appear explicitly in state matrix $\mathbf{A}$, the analytical approach can be applied to compute the eigenvalue sensitivities [21].

It is obvious from Table $\mathrm{V}$ that a DFIG parameter differs much in their sensitivities to different eigenvalues. Furthermore, the sensitivities also vary at different rotor speeds. This observation implies that simply adjusting only one DFIG parameter cannot ensure damping enhancements of several critical eigenvalue pairs at different rotor speeds. Correspondingly, the coordinated tuning of system parameters using advanced optimization technique should be considered to improve system stability in future work.

For $\lambda_{1,2}$, the most sensitive parameters are $R_{s}, \mathrm{~L}_{l s}$, and $L_{l r}$ as the real part of the sensitivities of $\lambda_{1,2}$ with respect to $R_{s}$, $L_{l s}$, and $L_{l r}$ are larger than the others. The increase in $R_{s}$ and decrease in $L_{l s}$ and $L_{l r}$ make $\lambda_{1,2}$ move toward left in the $s$-plane. For $\lambda_{3,4}$, the most sensitive parameter is $H_{g}$. A small positive perturbation in $H_{g}$ makes $\lambda_{3,4}$ shift toward the imaginary axis. However, as $\lambda_{3,4}$ are not the key modes for the oscillatory stability of the studied system, the increase in $H_{g}$ will not deteriorate the system stability. For $\lambda_{5,6}$, the most critical parameters are $R_{s}, R_{r}, L_{l s}$, and $L_{l r}$. The increase in $R_{r}$ and decrease in $L_{l s}$ and $L_{l r}$ will lead to $\lambda_{5,6}$ moving toward left in the $s$-plane. The decrease in $R_{s}$ at subsynchronous speed, while increase at synchronous and supersynchronous speed makes $\lambda_{5,6}$ shift toward left in the $s$-plane. For $\lambda_{7,8}$, only at synchronous speed, $\lambda_{7.8}$ is sensitive to the variation of $R_{r}$ and $L_{l s}$. For $\lambda_{9}$ and $\lambda_{10}$, the most sensitive parameters are $R_{r}$. The increase in $R_{r}$ leads to $\lambda_{9}$ shifting toward right and $\lambda_{10}$ moving toward left in the $s$-plane. $\lambda_{11}$ is insensitive to all these parameters listed in Table V.

\section{COMPUTER Simulation STUdy}

The preceding section presents theoretical analysis based on the mathematical model. In this section, we will present a series of computer simulations to verify the theoretical analysis. In particular, we will focus on the qualitative change of dynamics as $V_{w}$ is varied, as analyzed in Section IV. MATLAB/Simulink is used to establish the simulation model of DFIG system described in the foregoing section. All the components of the simulation model are built with standard electrical component blocks from the SimPowerSystems block set in MATLAB/Simulink library.

\section{A. Stable Operation}

Fig. 7(a)-(f) shows the time-domain waveforms of rotor speed $\omega_{r}$, dc-link voltage $U_{\mathrm{dc}}$, active power $P$, reactive power $Q$, stator current of phase A $i_{s a}$ and rotor current of phase A $i_{r a}$ when wind speed $V_{w}=11.1 \mathrm{~m} / \mathrm{s}$, rotor speed set point $\omega_{\text {ref }}=1.015$. It is shown that $\omega_{r}, U_{\mathrm{dc}}, P$, and $Q$ are nearly constant, $i_{s a}$ and $i_{r a}$ are sinusoidal. The system is stable and there is no oscillatory behavior.

\section{B. Oscillatory Instability}

When $V_{w}$ varies above a critical value, oscillatory behavior can occure in the studied system. Fig. 8 shows the corresponding steady-state time-domain waveforms, after a step increase of $0.9 \mathrm{~m} / \mathrm{s}(8.1 \%)$ is applied to $V_{w}\left(V_{w}=12 \mathrm{~m} / \mathrm{s}, \omega_{\text {ref }} \approx 1.1\right)$. It is shown that $\omega_{r}, U_{\mathrm{dc}}, P$, and $Q$ are no longer constant, but oscillate around the frequency of $3 \mathrm{~Hz} . i_{s a}$ and $i_{r a}$ are no more sineusoidal. In Section III, the nature of such oscillation is analyzed from a Hopf bifurcation perspective. It can be observed that Hopf bifurcation takes place at approximately the same wind speed condition as it does in our theoretical analysis, and the simulated periodic oscillations also match the earlier Hopf bifurcation analysis.

\section{Hopf Bifurcation Boundary}

The analysis in Section IV already shows that the oscillatory instability is essentially Hopf bifurcation induced one, through the eigenvalues $\lambda_{5,6}$. Sensitivity analysis also indicates the parameters, which have significant effects on the movement of $\lambda_{5,6}$, are $R_{s}, R_{r}, L_{l s}$, and $L_{l r}$. In this section, the stability boundary curves with respect to those critical parameters within the space of $K_{P \omega}$ versus $\omega_{r}$, where the conjugate eigenvalues $\lambda_{5,6}$ intersecting with the imaginary axis are mapped, which corrospond to the occurence of Hopf bifurcation. The Hopf bifurcation boundaries can be readily obtained by using the analytical means described in the earlier section. On the other hand, the boundaries obtained from simulations performed in MATLAB/Simulink are also given to verify the results from the theoretical analysis. 
TABLE V

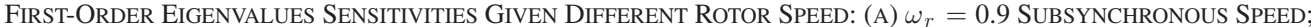

(B) $\omega_{r}=1$ SYNCHRONOUS SPEED; (C) $\omega_{r}=1.1$ SUBSYNCHRONOUS SPEED

(A)

\begin{tabular}{|c|c|c|c|c|c|c|c|}
\hline & $\lambda_{1,2}$ & $\lambda_{3,4}$ & $\lambda_{5,6}$ & $\lambda_{7,8}$ & $\lambda_{9}$ & $\lambda_{10}$ & $\lambda_{11}$ \\
\hline$R_{\mathrm{s}}$ & $-107 \pm \mathrm{j} 14.7$ & $-0.203 \pm j 1.67$ & $91.8 \pm \mathrm{j} 12.0$ & $-0.103 \pm \mathrm{j} 0.0256$ & 0 & 0 & 0 \\
\hline$R_{\mathrm{r}}$ & $0.0843 \pm \mathrm{j} 26.9$ & $-0.209 \pm \mathrm{j} 1.66$ & $-984.6 \pm \mathrm{j} 28.2$ & $-9.05 \mathrm{e}^{-3} \pm \mathrm{j} 0.0837$ & 10.5 & -4.131 & 0 \\
\hline$L_{\mathrm{ls}}$ & $25.5 \pm \mathrm{j} 0.749$ & $0.0625 \pm \mathrm{j} 0.887$ & $11.7 \pm \mathrm{j} 0.425$ & $0.0256 \pm \mathrm{j} 0.00871$ & 0.115 & -0.0451 & 0 \\
\hline$L_{\mathrm{lr}}$ & $23.4 \pm \mathrm{j} 0.757$ & $5.11 \mathrm{e}^{-4} \pm \mathrm{j} 0.0123$ & $13.3 \pm \mathrm{j} 0.716$ & $2.53 \mathrm{e}^{-3} \pm \mathrm{j} 0.000736$ & 0 & 0 & 0 \\
\hline$L_{\mathrm{m}}$ & $0.0444 \pm \mathrm{j} 0.00382$ & $0.227 \pm \mathrm{j} 0.363$ & $-0.102 \pm \mathrm{j} 0.167$ & $-0.0931 \pm \mathrm{j} 0.0106$ & 0.363 & -0.142 & 0 \\
\hline$H_{g}$ & $-4.84 \mathrm{e}^{-3} \pm \mathrm{j} 0.0432$ & $6.43 \pm \mathrm{j} 66.8$ & $0.0253 \pm \mathrm{j} 0.0144$ & $0.0348 \pm \mathrm{j} 0.160$ & 0 & 0 & 0 \\
\hline$H_{t}$ & 0 & $0.0412 \pm \mathrm{j} 0.660$ & $-0.0137 \pm \mathrm{j} 0.00152$ & $0.0354 \pm \mathrm{j} 0.161$ & 0 & 0 & 0 \\
\hline$K_{P \omega}$ & $1.69 \mathrm{e}^{-3} \pm \mathrm{j} 0.0168$ & $-0.585 \pm \mathrm{j} 0.0664$ & $0.0623 \pm j 0.00124$ & $-0.104 \pm \mathrm{j} 0.712$ & 0 & 0 & 0 \\
\hline$T_{\mathrm{i} \omega}$ & $5.32 \mathrm{e}^{-3} \pm \mathrm{j} 5.61 \mathrm{e}^{-4}$ & $-0.0134 \pm j 0.892$ & $4.58 \mathrm{e}^{-3} \pm \mathrm{j} 0.00483$ & $3.47 \mathrm{e}^{-3} \pm \mathrm{j} 7.23$ & 0 & 0 & 0 \\
\hline \multicolumn{8}{|c|}{ (B) } \\
\hline & $\lambda_{1,2}$ & $\lambda_{3,4}$ & $\lambda_{5,6}$ & $\lambda_{7,8}$ & $\lambda_{9}$ & $\lambda_{10}$ & $\lambda_{11}$ \\
\hline$R_{\mathrm{s}}$ & $-978.4 \pm j 16.8$ & $-0.255 \pm \mathrm{j} 0.335$ & $-2.05 \pm j 14.2$ & $-0.0169 \pm \mathrm{j} 0.0188$ & 0 & 0 & 0 \\
\hline$R_{\mathrm{r}}$ & $0.221 \pm j 22.2$ & $0.0795 \pm \mathrm{j} 0.822$ & $-984.1 \pm \mathrm{j} 22.5$ & $-0.936 \pm j 2.35$ & 14.2 & -5.58 & 0 \\
\hline$L_{\mathrm{ls}}$ & $23.2 \pm \mathrm{j} 0.731$ & $0.0795 \pm \mathrm{j} 0.984$ & $12.9 \pm \mathrm{j} 0.547$ & $1.14 \pm j 0.169$ & 0.0100 & -0.00394 & 0 \\
\hline$L_{\mathrm{lr}}$ & $21.3 \pm \mathrm{j} 0.728$ & $-3.04 \mathrm{e}^{-3} \pm j 5.80 \mathrm{e}^{-3}$ & $15.5 \pm \mathrm{j} 0.677$ & $0.0123 \pm \mathrm{j} 0.0374$ & 0 & 0 & 0 \\
\hline$L_{\mathrm{m}}$ & $0.0396 \pm \mathrm{j} 0.00371$ & $-0.0279 \pm \mathrm{j} 0.273$ & $0.303 \pm \mathrm{j} 0.642$ & $-0.239 \pm \mathrm{j} 0.0188$ & -0.0391 & 0.0154 & 0 \\
\hline$H_{g}$ & $-6.88 \mathrm{e}^{-3} \pm \mathrm{j} 0.0396$ & $6.47 \pm \mathrm{j} 66.8$ & $-0.0110 \pm j 1.00 \mathrm{e}^{-4} \mathrm{i}$ & $0.0353 \pm \mathrm{j} 0.164$ & 0 & 0 & 0 \\
\hline$\hat{H_{t}}$ & 0 & $0.0387 \pm \mathrm{j} 0.661$ & $-0.0103 \pm j 1.00 \mathrm{e}^{-4} \mathrm{i}$ & $0.0359 \pm \mathrm{j} 0.166$ & 0 & 0 & 0 \\
\hline$K_{P \omega}$ & $2.49 \mathrm{e}^{-3} \pm \mathrm{j} 0.0153$ & $-0.571 \pm \mathrm{j} 0.0588$ & $0.0443 \pm j 3.30 \mathrm{e}^{-4}$ & $-0.101 \pm \mathrm{j} 0.732$ & 0 & 0 & 0 \\
\hline$T_{\mathrm{i} \omega}$ & $4.87 \mathrm{e}^{-3} \pm \mathrm{j} 8.25 \mathrm{e}^{-4}$ & $1.09 \mathrm{e}^{-3} \pm \mathrm{j} 0.891$ & $0.0349 \pm \mathrm{j} 0.0344$ & $-0.0409 \pm \mathrm{j} 7.29$ & 0 & 0 & 0 \\
\hline \multicolumn{8}{|c|}{$(\mathrm{C})$} \\
\hline & $\lambda_{1,2}$ & $\lambda_{3,4}$ & $\lambda_{5,6}$ & $\lambda_{7,8}$ & $\lambda_{9}$ & $\lambda_{10}$ & $\lambda_{11}$ \\
\hline$R_{\mathrm{s}}$ & $-900.2 \pm j 17.4$ & $-0.358 \pm \mathrm{j} 0.800$ & $-80.3 \pm \mathrm{j} 15.1$ & $0.0908 \pm \mathrm{j} 0.0211$ & 0 & 0 & 0 \\
\hline$R_{\mathrm{r}}$ & $0.273 \pm \mathrm{j} 18.7$ & $0.753 \pm \mathrm{j} 1.76$ & $-985.7 \pm \mathrm{j} 17.3$ & $-0.0254 \pm \mathrm{j} 0.0663$ & 18.9 & -7.47 & 0 \\
\hline$L_{\mathrm{ls}}$ & $21.3 \pm \mathrm{j} 0.695$ & $0.234 \pm \mathrm{j} 1.81$ & $15.7 \pm \mathrm{j} 1.26$ & $0.0403 \pm \mathrm{j} 0.0159$ & -0.307 & 0.121 & 0 \\
\hline$L_{\mathrm{lr}}$ & $19.5 \pm \mathrm{j} 0.684$ & $-0.0168 \pm \mathrm{j} 0.0470$ & $17.3 \pm \mathrm{j} 0.611$ & $-1.86 \mathrm{e}^{-3} \pm \mathrm{j} 0.00160$ & 0 & 0 & 0 \\
\hline$L_{\mathrm{m}}$ & $0.0353 \pm \mathrm{j} 0.00351$ & $-0.437 \pm \mathrm{j} 0.321$ & $0.373 \pm \mathrm{j} 0.0127$ & $0.105 \pm \mathrm{j} 0.00833$ & -0.606 & 0.239 & 0 \\
\hline$H_{g}$ & $-9.29 \mathrm{e}^{-3} \pm \mathrm{j} 0.0365$ & $6.43 \pm \mathrm{j} 66.8$ & $0.0266 \pm \mathrm{j} 0.0252$ & $0.0368 \pm \mathrm{j} 0.159$ & 0 & 0 & 0 \\
\hline$H_{t}$ & 0 & $0.0418 \pm \mathrm{j} 0.660$ & $-0.0135 \pm \mathrm{j} 0.00107$ & $0.0373 \pm \mathrm{j} 0.161$ & 0 & 0 & 0 \\
\hline$K_{P \omega}$ & $3.43 \mathrm{e}^{-3} \pm \mathrm{j} 0.0142$ & $-0.588 \pm j 0.0473$ & $0.0623 \pm \mathrm{j} 0.00943$ & $-0.103 \pm \mathrm{j} 0.712$ & 0 & 0 & 0 \\
\hline$T_{\mathrm{i} \omega}$ & $4.50 \mathrm{e}^{-3} \pm \mathrm{j} 0.00113$ & $0.0121 \pm \mathrm{j} 0.892$ & $-4.83 \mathrm{e}^{-3} \pm \mathrm{j} 0.00201$ & $-0.0118 \pm j 7.24$ & 0 & 0 & 0 \\
\hline
\end{tabular}

Fig. 9(a)-(d) shows the Hopf bifurcation boundaries in the parameter space of $K_{P \omega}$ versus $\omega_{r}$ under different values of $R_{s}, R_{r}, L_{l s}$, and $L_{l r}$, respectively, which clearly illustrates the effect of those sensitive parameters on the Hopf bifurcation boundaries. Area below the curves corresponds to stable operation and above that to unstable operation. On top of these curves, the system loses stability via Hopf bifurcation.

As shown in Fig. 9, the simulation results agree well with the analytical results. Also, we can generally observe that around synchronous speed, the critical value of $K_{P \omega}$ is the largest, and does not change so significantly in different system parameter conditions. When $\omega_{r}$ is away from synchronous speed (e.g., in $0.7-0.9$ or around 1.1), the critical value of $K_{P \omega}$ decreases as the value of $\omega_{r}$ increases, and Hopf bifurcation boundaries have considerable changes in different system parameter conditions. The point marked with "*" is the stable operating point before the bifurcation occurs. At subsynchronous speed, the Hopf bifurcation margin becomes smaller as $R_{s}$ increases. While at supersynchronous speed, the Hopf bifurcation margin becomes larger as $R_{s}$ increases. For all studied region of rotor speed, the Hopf bifurcation margin becomes larger, as $R_{r}$ increases, while $L_{l s}$ and $L_{l r}$ decrease.

\section{Discussion}

The simulation results have confirmed the theoretical analysis based on derived model and Jacobian matrix. The simulation results show that the oscillatory behavior with the nature of Hopf bifurcation can happen due to reason like varying wind speed. The observed oscillation is primarily due to the varying electromagnetic torque, since the mechanical one is fixed. Such oscillation of the electromagnetic torque is related to the variations of the magnitude and direction of the stator and rotor flux-linkage vectors [22], [23], which is not focused herein, but will be investigated in our future scope.

Besides the wind speed and control parameters, Hopf bifurcation is also sensitive to other system parameters, and the impact of different parameters on the Hopf bifurcation margin at different rotor speeds is different. For the studied system, Hopf bifurcation boundaries for the eigenvalues $\lambda_{5,6}$ show that such bifurcation can happen particularly when $R_{s}, L_{l s}$, and $L_{l r}$ increase, while $R_{r}$ decreases at subsynchronous speed. At supersynchronous speed, the increase of $L_{l s}$ and $L_{l r}$, while decrease of $R_{s}$ and $R_{r}$ may lead to such Hopf bifurcation. Hence, simply increasing $R_{s}$ cannot enhance the Hopf bifurcation margin at different rotor speeds, and it is recommended to choose large value of $R_{r}$, while small value of $L_{l s}$ and $L_{l r}$ to enlarge such Hopf bifurcation margin. These are the important characteristics for a DFIG wind turbine system, and very useful for the operators of such system to be careful in situations, where critical parameters may be changed. Hopf bifurcation boundaries for other eigenvalues have also been studied. Though different bifurcation boundaries will be exhibited for different eigenvalues, 


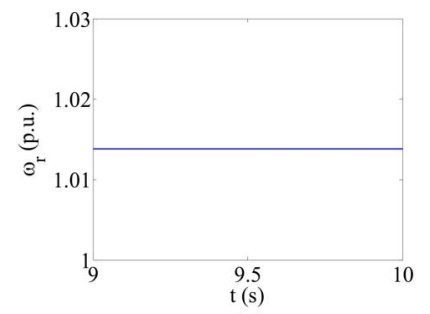

(a)

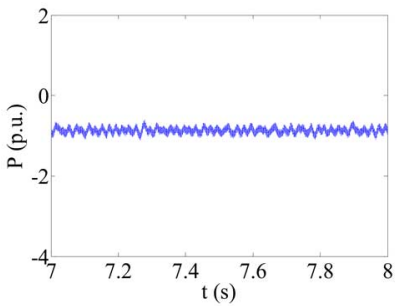

(c)

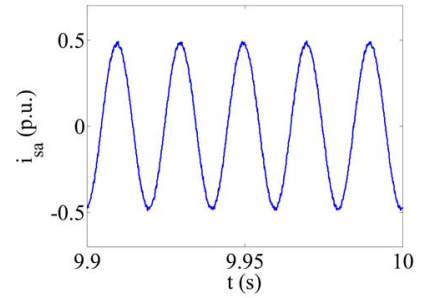

(e)

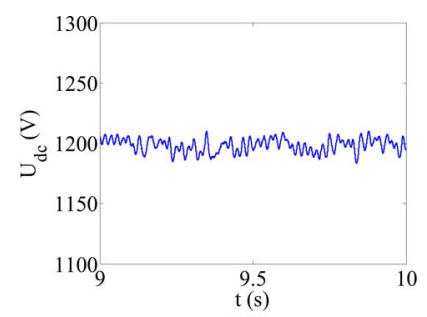

(b)

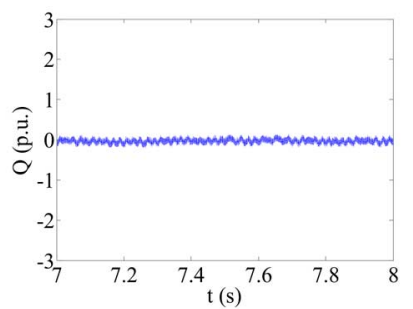

(d)

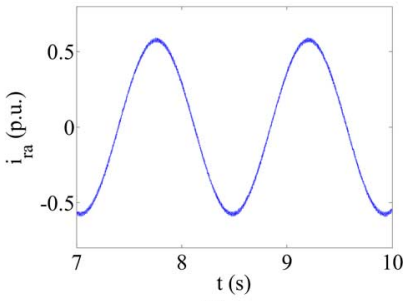

(f)
Fig. 7. Simulation results when DFIG works in stable operation. (a) Rotor speed $\omega_{r}$. (b) DC-link voltage $U_{\mathrm{dc}}$. (c) Active power $P$. (d) Reactive power $Q$. (e) Phase A of stator current $i_{s a}$. (f) Phase A of rotor current $i_{r a}$.

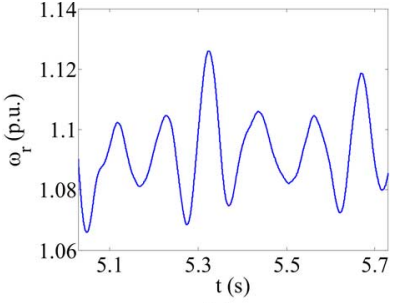

(a)

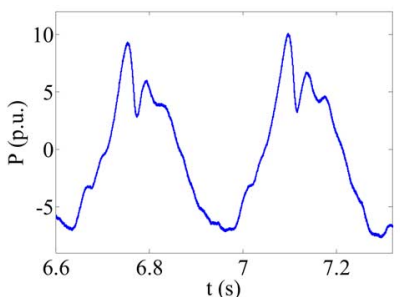

(c)

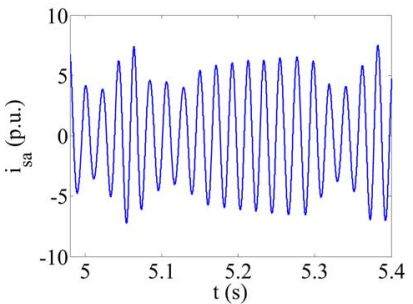

(e)

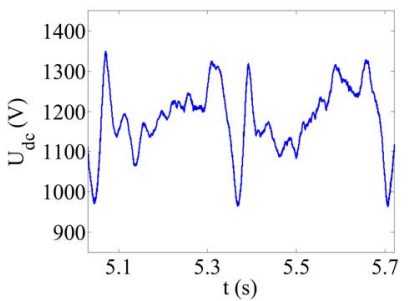

(b)

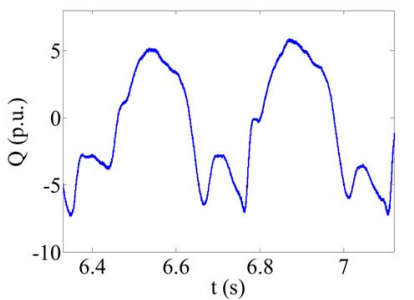

(d)

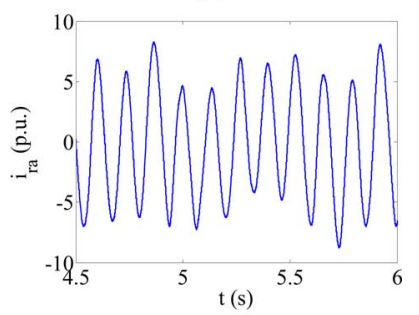

(f)
Fig. 8. Simulation results when oscillatory instability occurs. (a) Rotor speed $\omega_{r}$. (b) DC-link voltage $U_{\mathrm{dc}}$. (c) Active power $P$. (d) Reactive power $Q$. (e) Phase A of stator current $i_{s a}$. (f) Phase A of rotor current $i_{r a}$.

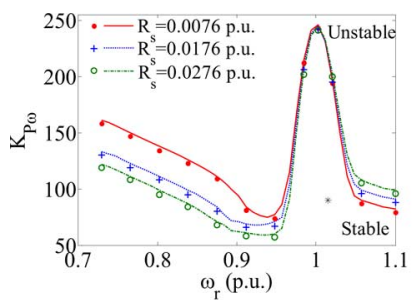

(a)

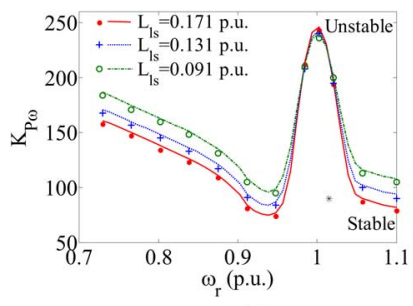

(c)

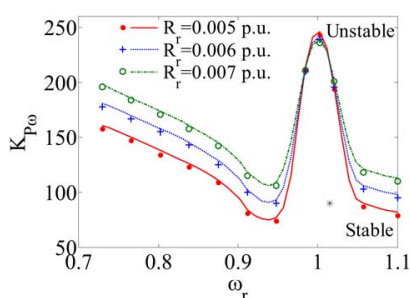

(b)

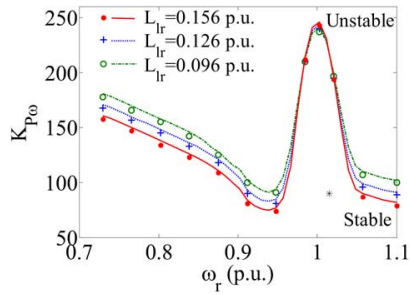

(d)
Fig. 9. Hopf bifurcation boundaries in the parameter space of $K_{P \omega}$ versus $\omega_{r}$ for (a) different values of stator resistance $R_{s}$, (b) mutual inductance $R_{r}$, (c) stator leakage inductance $L_{l s}$, and (d) rotor leakage inductance $L_{l r}$. Results from analysis are denoted by the solid line. Results from simulations are represented by "•", "+," and "०". The dot “*” is the stable operating point.

in general, a varying style along with rotor speed can be clearly observed.

When the wind speed is higher than the rated value, the power limitation is activated. It is obvious from the results in Fig. 5 that the system is more stable and Hopf bifurcation can hardly happen. Therefore, the bifurcation boundary at higher wind speed has not been analyzed in this paper.

\section{CONCLUSION}

DFIG has been one of the popular types for high-power applications of wind power generation. However, the detailed nonlinear dynamics of this system, so far, has not been thoroughly investigated. In this paper, a detailed DFIG wind turbine model including two-mass drive train, pitch control, induction generator, back-to-back PWM converters, and vector-control loops was developed. The Jacobian matrix was also derived for small-signal-stability analysis purpose. Bifurcation and eigenvalue sensitivity analysis based on both theoretical analysis and computer simulations showed that DFIG wind turbine can loose stability via a Hopf bifurcation. Further analysis showed that the impact of different DFIG parameters on different critical eigenvalue pairs at different rotor speeds was different. The most sensitive parameters to the Hopf bifurcation of a DFIG wind turbine system can be identified through eigenvalue sensitivity analysis. Moreover, the Hopf bifurcation boundaries with respect to those critical parameters have also been analyzed that can facilitate parameterizing the DFIG wind turbine system to ensure stable operation. The analyses in this paper provide insights into DFIG oscillatory stability that can be important for both manufacturer and system operators in designing or practically operating such wind turbines concerning their impact on power system small-signal stability. 


\section{APPENDIX}

\section{JACOBIAN MATRIX}

$J_{11}=D\left(R_{s} L_{r}+L_{m} \frac{\partial u_{d r}}{\partial i_{d s}}\right) \quad J_{112}=D L_{m} \frac{\partial u_{d r}}{\partial x_{u s}}$

$\left.J_{12}=D\left[\left(\omega_{s}-\omega_{r 0}\right) L_{m}^{2}-\omega_{s} L_{s} L_{r}+L_{m} \frac{\partial u_{d r}}{\partial i_{q s}}\right)\right]$

$J_{13}=D\left(-R_{r} L_{m}+L_{m} \frac{\partial u_{d r}}{\partial i_{d r}}\right)$

$\left.J_{14}=D\left[-\omega_{r 0} L_{r} L_{m}+L_{m} \frac{\partial u_{d r}}{\partial i_{q r}}\right)\right]$

$\left.J_{15}=D\left[-L_{m}^{2} I_{q s 0}-L_{r} L_{m} I_{q r 0}+L_{m} \frac{\partial u_{d r}}{\partial \omega_{r}}\right)\right]$

$J_{17}=D L_{m} \frac{\partial u_{d r}}{\partial x_{\omega}} \quad J_{19}=D L_{m} \frac{\partial u_{d r}}{\partial \theta_{\omega}}$

$J_{110}=D L_{m} \frac{\partial u_{d r}}{\partial \omega_{t}} \quad J_{111}=D L_{m} \frac{\partial u_{d r}}{\partial \beta}$

$\left.J_{21}=D\left[-\left(\omega_{s}-\omega_{r 0}\right) L_{m}^{2}+\omega_{s} L_{s} L_{r}+L_{m} \frac{\partial u_{q r}}{\partial i_{d s}}\right)\right]$

$J_{22}=D\left(R_{s} L_{r}+L_{m} \frac{\partial u_{q r}}{\partial i_{q s}}\right)$

$\left.J_{23}=D\left[\omega_{r 0} L_{r} L_{m}+L_{m} \frac{\partial u_{q r}}{\partial i_{d r}}\right)\right]$

$J_{24}=D\left(-R_{r} L_{m}+L_{m} \frac{\partial u_{q r}}{\partial i_{q r}}\right) \quad J_{27}=D L_{m} \frac{\partial u_{q r}}{\partial x_{\omega}}$

$J_{29}=D L_{m} \frac{\partial u_{q r}}{\partial \theta_{\omega}}$

$\left.J_{25}=D\left[L_{m}^{2} I_{d s 0}+L_{r} L_{m} I_{d r 0}+L_{m} \frac{\partial u_{q r}}{\partial \omega_{r}}\right)\right]$

$J_{210}=D L_{m} \frac{\partial u_{q r}}{\partial \omega_{t}} \quad J_{211}=D L_{m} \frac{\partial u_{q r}}{\partial \beta}$

$J_{212}=D L_{m} \frac{\partial u_{q r}}{\partial x_{u s}} \quad J_{31}=D\left(-R_{s} L_{m}-L_{s} \frac{\partial u_{d r}}{\partial i_{d s}}\right)$

$\left.J_{32}=D\left[\omega_{r 0} L_{s} L_{m}-L_{s} \frac{\partial u_{d r}}{\partial i_{q s}}\right)\right]$

$J_{33}=D\left(R_{r} L_{s}-L_{s} \frac{\partial u_{d r}}{\partial i_{d r}}\right)$

$\left.J_{34}=D\left[\omega_{s} L_{m}^{2}-\left(\omega_{s}-\omega_{r 0}\right) L_{s} L_{r}-L_{s} \frac{\partial u_{d r}}{\partial i_{q r}}\right)\right]$

$\left.J_{35}=D\left[L_{s} L_{m} I_{q s 0}+L_{s} L_{r} I_{q r 0}-L_{s} \frac{\partial u_{d r}}{\partial \omega_{r}}\right)\right]$

$J_{37}=-D L_{s} \frac{\partial u_{d r}}{\partial x_{\omega}} \quad J_{39}=D L_{m} \frac{\partial u_{d r}}{\partial \theta_{\omega}}$

$J_{310}=-D L_{s} \frac{\partial u_{d r}}{\partial \omega_{t}} \quad J_{311}=-D L_{s} \frac{\partial u_{d r}}{\partial \beta}$
$J_{312}=-D L_{s} \frac{\partial u_{d r}}{\partial x_{u s}} \quad J_{41}=D\left(-\omega_{r 0} L_{s} L_{m}-L_{s} \frac{\partial u_{q r}}{\partial i_{d s}}\right)$

$J_{42}=D\left(-R_{s} L_{m}-L_{s} \frac{\partial u_{q r}}{\partial i_{q s}}\right) \quad J_{44}=D\left(R_{r} L_{s}-L_{s} \frac{\partial u_{q r}}{\partial i_{q r}}\right)$

$\left.J_{43}=D\left[-\omega_{s} L_{m}^{2}+\left(\omega_{s}-\omega_{r 0}\right) L_{s} L_{r}-L_{s} \frac{\partial u_{q r}}{\partial i_{d r}}\right)\right]$

$\left.J_{45}=D\left[-L_{s} L_{m} I_{d s 0}-L_{s} L_{r} I_{d r 0}-L_{s} \frac{\partial u_{q r}}{\partial \omega_{r}}\right)\right]$

$J_{47}=-D L_{s} \frac{\partial u_{q r}}{\partial x_{\omega}} \quad J_{49}=-D L_{s} \frac{\partial u_{q r}}{\partial \theta_{\omega}}$

$J_{410}=-D L_{s} \frac{\partial u_{q r}}{\partial \omega_{t}} \quad J_{411}=-D L_{s} \frac{\partial u_{q r}}{\partial \beta}$

$J_{412}=-D L_{s} \frac{\partial u_{q r}}{\partial x_{u s}} \quad J_{51}=-\frac{L_{m}}{2 H_{g}} I_{q r 0}$

$J_{52}=\frac{L_{m}}{2 H_{g}} I_{d r 0} \quad J_{53}=\frac{L_{m}}{2 H_{g}} I_{q s 0} \quad J_{54}=-\frac{L_{m}}{2 H_{g}} I_{d s 0}$

$J_{55}=-\frac{D_{\mathrm{sh}} \omega_{b}+B}{2 H_{g}} \quad J_{59}=\frac{K_{\mathrm{sh}}}{2 H_{g}} \quad J_{510}=\frac{D_{\mathrm{sh}} \omega_{b}}{2 H_{g}}$

$J_{61}=-\frac{1}{G_{0}}\left(I_{d r 0} \frac{\partial u_{d r}}{\partial i_{d s}}+I_{q r 0} \frac{\partial u_{q r}}{\partial i_{d s}}\right)$

$J_{62}=-\frac{1}{G_{0}}\left(I_{d r 0} \frac{\partial u_{d r}}{\partial i_{q s}}+I_{q r 0} \frac{\partial u_{q r}}{\partial i_{q s}}\right)$

$J_{63}=-\frac{1}{G_{0}}\left(U_{d r 0}+I_{d r 0} \frac{\partial u_{d r}}{\partial i_{d r}}+I_{q r 0} \frac{\partial u_{q r}}{\partial i_{d r}}\right)$

$J_{64}=-\frac{1}{G_{0}}\left(U_{q r 0}+I_{d r 0} \frac{\partial u_{d r}}{\partial i_{q r}}+I_{q r 0} \frac{\partial u_{q r}}{\partial i_{q r}}\right)$

$J_{65}=-\frac{1}{G_{0}}\left(I_{d r 0} \frac{\partial u_{d r}}{\partial \omega_{r}}+I_{q r} \frac{\partial u_{q r}}{\partial \omega_{r}}\right)$

$J_{66}=-\frac{W_{0}}{G_{0}^{2}} \frac{\partial G}{\partial U_{\mathrm{dc}}}+\frac{\partial W}{G_{0} \partial U_{\mathrm{dc}}}$

$J_{67}=-\frac{1}{G_{0}}\left(I_{d r 0} \frac{\partial u_{d r}}{\partial x_{\omega}}+I_{q r 0} \frac{\partial u_{q r}}{\partial x_{\omega}}\right)$

$J_{68}=-\frac{W_{0}}{G_{0}^{2}} \frac{\partial G}{\partial x_{u}}+\frac{\partial W}{G_{0} \partial x_{u}}$

$J_{69}=-\frac{1}{G_{0}}\left(I_{d r 0} \frac{\partial u_{d r}}{\partial \theta_{\omega}}+I_{q r 0} \frac{\partial u_{q r}}{\partial \theta_{\omega}}\right)$

$J_{610}=-\frac{1}{G_{0}}\left(I_{d r 0} \frac{\partial u_{d r}}{\partial \omega_{t}}+I_{q r 0} \frac{\partial u_{q r}}{\partial \omega_{t}}\right)$

$J_{611}=-\frac{1}{G_{0}}\left(I_{d r 0} \frac{\partial u_{d r}}{\partial \beta}+I_{q r 0} \frac{\partial u_{q r}}{\partial \beta}\right)$

$J_{612}=-\frac{1}{G_{0}}\left(I_{d r 0} \frac{\partial u_{d r}}{\partial x_{u s}}+I_{q r 0} \frac{\partial u_{q r}}{\partial x_{u s}}\right)$

$J_{75}=-\frac{K_{P \omega}}{T_{I \omega}} \quad J_{710}=\frac{K_{P \omega}}{2 T_{I \omega}}\left(\frac{T_{m}}{K_{o p t}}\right)^{-0.5} \frac{\partial T_{m}}{\partial \omega_{t}}$ 


$$
\begin{aligned}
& J_{86}=-\frac{K_{P v}}{T_{I v}} \quad J_{711}=\frac{K_{P \omega}}{2 T_{I \omega}}\left(\frac{T_{m}}{K_{\mathrm{opt}}}\right)^{-0.5} \frac{\partial T_{m}}{\partial \beta} \\
& J_{95}=-\omega_{b} \quad J_{910}=\omega_{b} \\
& J_{105}=\frac{D_{\mathrm{sh}} \omega_{b}}{2 H_{t}} \quad J_{109}=-\frac{K_{\mathrm{sh}}}{2 H_{t}} \\
& J_{1010}=\frac{1}{2 H_{t}}\left(\frac{\partial T_{m}}{\partial \omega_{t}}-D_{\mathrm{sh}} \omega_{b}\right) \quad J_{1011}=\frac{1}{2 H_{t}} \frac{\partial T_{m}}{\partial \beta} \\
& J_{1101}=\frac{1}{T_{\beta}} \frac{\partial \beta_{\mathrm{ref}}}{\partial i_{d s}} \quad J_{1102}=\frac{1}{T_{\beta}} \frac{\partial \beta_{\mathrm{ref}}}{\partial i_{q s}} \\
& J_{116}=\frac{1}{T_{\beta}} \frac{\partial \beta_{\mathrm{ref}}}{\partial U_{\mathrm{dc}}} \quad J_{118}=\frac{1}{T_{\beta}} \frac{\partial \beta_{\mathrm{ref}}}{\partial x_{u}} \\
& J_{1111}=-\frac{1}{T_{\beta}} \quad J_{1113}=\frac{1}{T_{\beta}} \frac{\partial \beta_{\mathrm{ref}}}{\partial x_{\beta}} \\
& J_{131}=\frac{K_{P \beta}}{T_{I \beta}} \frac{\partial P_{g}}{\partial i_{d s}} \quad J_{132}=\frac{K_{P \beta}}{T_{I \beta}} \frac{\partial P_{g}}{\partial i_{q s}} \\
& J_{136}=\frac{K_{P \beta}}{T_{I \beta}} \frac{\partial P_{g}}{\partial U_{\mathrm{dc}}} \quad J_{138}=\frac{K_{P \beta}}{T_{I \beta}} \frac{\partial P_{g}}{\partial x_{u}}, \\
& \text { where } G=\frac{2 C_{\mathrm{dc}}}{3 \omega_{b}} U_{\mathrm{dc}}-\frac{\sqrt{2} L K_{P v}}{\sqrt{3} m \omega_{b}} i_{d L}^{\varepsilon} \\
& W=i_{d L}^{\varepsilon}\left[U_{s}-R_{L} i_{d L}^{\varepsilon}-\frac{\sqrt{2} L K_{P v}}{\sqrt{3} m \omega_{b} T_{I v}}\left(U_{\mathrm{dcref}}-U_{\mathrm{dc}}\right)\right. \\
& \left.+\omega_{s} L I_{q L \mathrm{ref}}\right]-I_{q L \mathrm{ref}}\left(R_{L} I_{q L \mathrm{ref}}+\omega_{s} L i_{d L}^{\varepsilon}\right) \\
& -\left(u_{d r} i_{d r}+u_{q r} i_{q r}\right) \text {. }
\end{aligned}
$$

\section{REFERENCES}

[1] J. Nagy, L. Matakas, and E. Masada, "Application of the theory of chaos in PWM technique of induction motors," in Proc. Int. Conf. Power Electron., 1995, pp. 58-63.

[2] J. H. Chen, K. T. Chau, and C. C. Chan, "Analysis of chaos in currentmode-controlled dc drive systems," IEEE Trans. Ind. Electron., vol. 47, no. 1, pp. 67-76, Feb. 2000

[3] Z. Li, J. B. Park, Y. H. Joo, B. Zhang, and G. R. Chen, "Bifurcation and chaos in a permanent-magnet synchronous motor," IEEE Trans. Circuits Syst. I, Fundam. Theory Appl., vol. 49, no. 3, pp. 383-387, Mar. 2002.

[4] Y. Gao and K. T. Chau, "Hopf bifurcation and chaos in synchronous reluctance motor drives," IEEE Trans. Energy Convers., vol. 19, no. 2, pp. 296-302, Jun. 2004.

[5] F. Mei and B. C. Pal, "Modal analysis of grid-connected doubly fed induction generators," IEEE Trans. Energy Convers, vol. 22, no. 3, pp. 728-736, Sep. 2007

[6] F. Wu, X. P. Zhang, K. Godfrey, and P. Ju, "Small signal stability analysis and optimal control of a wind turbine with doubly fed induction generator," IET Gen. Trans. Distr., vol. 1, no. 5, pp. 751-760, 2007.

[7] C. Wang and L. Shi, "Small signal stability analysis considering gridconnected wind farms of DFIG type," in Proc. IEEE Power and Energy Soc. Gen. Meeting, Jul. 2008, pp. 20-24.

[8] G. Tsourakis, B. M. Nomikos, and C. D. Vournas, "Effect of wind parks with doubly fed asynchronous generators on small-signal stability," Electr. Power Syst. Res., vol. 79, pp. 190-200, 2009.

[9] L. Yang, X. Ma, and D. Dai, "Hopf bifurcation in doubly fed induction generator under vector control," Chaos, Sol. Fract., vol. 41, no. 5, pp. 2741-2749, 2009.

[10] A. D. Hansen, P. Sørensen, F. Iov, and F. Blaabjerg, "Control of variable speed wind turbines with doubly-fed induction generators," Wind Eng., vol. 28 , no. 4, pp. 411-434, 2004.
[11] C. W. Liu, H. Q. Weng, X. D. Sun, and F. H. Li, "Research of stability of double fed induction motor vector control system," in Proc. 5th Int. Conf. on Electr. Machines Syst., Aug. 2001, vol. 2, pp. 1203-1206.

[12] P. Pourbeik (convener), WG C4.601, "Modeling and dynamic behavior of wind generation as it relates to power system control and dynamic performance," CIGRE, Paris, France, Tech. Brochure 328, Aug. 2007.

[13] L. Rouco and J. L. Zamora, "Dynamic patterns and model order reduction in small-signal models of doubly fed induction generators for wind power applications," in Proc. IEEE PES Gen. Meeting, 2006, pp. 1-8.

[14] P. C. Krause, O. Wasynczuk, and S. D. Sudhoff,, Analysis of Electric Machinery and Drive Systems. Piscataway, NJ: IEEE Press, 2002.

[15] V. Akhmatov, Induction Generators for Wind Power. Brentwood, Essex, U.K: Multi-science Publ. Co. Ltd, 2005.

[16] R. Cardenas, "Control of wind turbines using switched reluctance generators," Ph.D. thesis, Univ. Nottingham, U.K., 1996.

[17] R. Pena, J. C. Clare, and G. M. Asher, "Doubly fed induction generator using back-to-back PWM converters and its application to variable speed wind-energy generation," in Proc. Inst. Elect. Eng. Electr. Power Appl., May 1996, vol. 143, no. 3, pp. 231-241.

[18] P. Ledesma and J. Usaola, "Doubly fed induction generator model for transient stability analysis," IEEE Trans. Energy Convers., vol. 20, no. 2, pp. 388-397, Jun. 2005.

[19] Z. Y. Dong, "Advanced methods for power system small signal stability and control," Ph.D. thesis, Sydney Univ., Sydney, Australia, 1999, pp. S4S57.

[20] J. Ma and Z. Y. Dong, "Eigenvalue Sensitivity Analysis for Probabilistic Small Signal Stability Assessment," presented at the IET APSCOM'06, Hong Kong, China.

[21] Z. Y. Dong, C. K. Pang, and P. Zhang, "Power System Sensitivity Analysis for Probabilistic Small Signal Stability Assessment in a Deregulated Environment," Int. J. Control, Automat. Syst., vol. 3, no. 2, pp. 355-362, Jun. 2005.

[22] M. Alakula, B. Peterson, and J. Valis, "Damping of oscillations in induction machines," in Proc. 23rd Annu. IEEE Power Electron. Spec. Conf., Jun. 1992, vol. 1, pp. 133-138.

[23] J. Zhang, M. F. Rahman, and L. Tang, "Modified direct torque controlled induction generator with space vector modulation for integrated starter alternator," in Proc. 4th Int. Power Electron. Motion Control Conf., Aug. 2004, vol. 1, pp. 405-408.

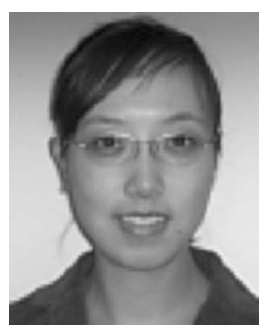

Lihui Yang received the Ph.D. degree in electrical engineering from Xi'an Jiaotong University, Xi'an, Shaanxi, China, in 2010.

During 2008-2009, she was a Visiting Ph.D. Student at the Center for Electric Technology, Technical University of Denmark. She is currently an Assistant Professor at Xi' an Jiaotong University. Her research interests include stability and control of wind power generation.

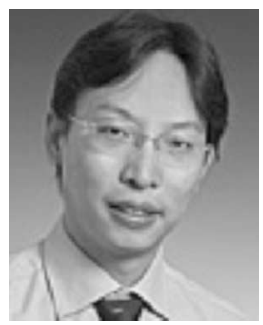

Zhao Xu (S'00-M'06) received the Ph.D. degree in electrical engineering from The University of Queensland, Australia, in 2006.

From 2006-2009, he was an Assistant at the Center for Electric Technology, Technical University of Denmark, where he became an Associate Professor. Since 2010, he has been with Hong Kong Polytechnic University, Kowloon, Hong Kong. His research interests include demand side, grid integration of wind power, electricity market planning and management, and $\mathrm{AI}$ applications. 


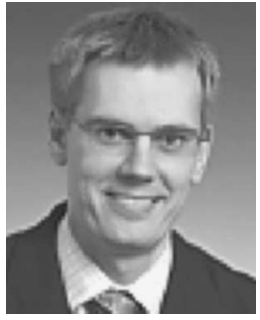

Jacob Østergaard (M'95-SM'09) received the M.Sc. degree in electrical engineering from the Technical University of Denmark, Lyngby, Denmark, in 1995.

$\mathrm{He}$ is currently a Professor and the Head of the Center for Electric Technology, Department of Electrical Engineering, Technical University of Denmark. His research interests include integration of renewable energy, control architecture for future power system, and demand side.

Prof. Østergaard is engaged with several professional organizations, including the EU SmartGrids Advisory Council.

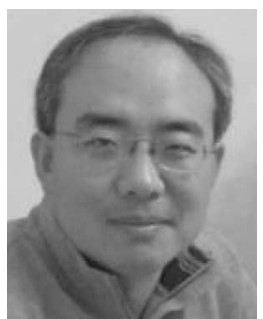

Zhao Yang Dong (M'99-SM'06) received the Ph.D. degree from The University of Sydney, Sydney, Australia, in 1999.

He was engaged in various academic positions at The University of Queensland, Australia and National University of Singapore. He is currently engaged at Hong Kong Polytechnic University, Kowloon, Hong Kong. He is also engaged in various industrial positions with Powerlink Queensland, Virginia, and Transend Networks, Tasmania, Australia (both are transmission network service providers in corresponding states). His research interests include power system planning, power system security assessment, power system stability and control, power system load modeling, electricity market, and computational intelligence and its application in power engineering.

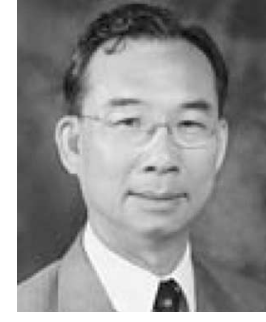

Kit Po Wong (M'87-SM'90-F'02) received the M.Sc., Ph.D., and D.Eng. degrees from the Institute of Science and Technology, University of Manchester, Manchester, U.K., in 1972, 1974, and 2001, respectively.

From 1974 to 2004, he was at The University of Western Australia, Perth, Australia, where he is currently an Adjunct Professor. He was the Head of the Department of Electrical Engineering, The Hong Kong Polytechnic University, Kowloon, Hong Kong, where he has been the Chair Professor, since 2002. His research interests include computation intelligence applications to power system analysis, planning and operations, as well as power market analysis.

Prof. Wong received three Sir John Madsen Medals (1981, 1982, and 1988) from the Institution of Engineers, Australia (IEAust), the 1999 Outstanding Engineer Award from IEEE Power Chapter Western Australia, and the 2000 IEEE Third Millennium Award. He was a Co-Technical Chairman of the IEEE International Conference on Machine Learning and Cybernetics (ICMLC) 2004 and the General Chairman of IEEE/CSEE PowerCon2000. He was an Editor-inChief of IEE Proceedings in Generation, Transmission and Distribution and the Editor (Electrical) of the Transactions of Hong Kong Institution of Engineers. He is a Fellow of the Institution of Engineering and Technology (IET), the Hong Kong Institution of Engineers (HKIE), and the IEAust.

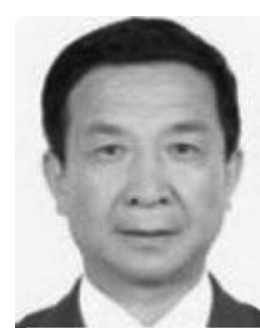

Xikui Ma received the B.E. and M.Sc. degrees in electrical engineering from Xi'an Jiaotong University, Xi' an, China, in 1982 and 1985, respectively.

In 1985 , he joined the Xi' an Jiaotong University as a Lecturer, where he has been a Professor, since 1992. His current research interests include electromagnetic field theory and its application, numerical methods, modeling of magnetic components, chaotic dynamics and its applications in power electronics, and applications of digital control in power electronics. 